\title{
Renal abscess in childhood: a case report 6 years girl
}

\author{
Çocukluk çă̆ında renal apse; 6 yaș kız hasta vaka sunumu
}

\author{
Fatma Tugba Güvenç ${ }^{1}$, Enes Salı², Sevinç Kalın³, Bahri Elmas ${ }^{4}$, Zekeriya İlçe ${ }^{5}$ \\ 1 Health Sciences University, Ümraniye Training and Research Hospital Pediatric Surgery, İstanbul, Turkey \\ 2 Health Sciences University, Ümraniye Training and Research Hospital Pediatric Infectious Diseases, İstanbul, Turkey \\ 3 Health Sciences University, Ümraniye Training and Research Hospital Pediatric Radiology, İstanbul, Turkey \\ 4 Sakarya University, Faculty of Medicine, Department of Pediatrics, Sakarya, Turkey \\ 5 Health Sciences University, Ümraniye Training and Research Hospital, Pediatric Surgery, İstanbul, Turkey
}

Submitted (Geliş tarihi): 2021-07-16 Accepted (Kabul tarihi): 2021-12-28

\section{Correspondence / Yazışma} Fatma Tuğba Güvenç Elmalıkent, Adem Yavuz Cd. 34764

Ümraniye, İstanbul/ Turkey

E-posta: tgbgvnc@gmail.com

Tel: +905321607549

\section{ORCID \\ F.T.G. $\quad$ 0000-0002-9464-9737 \\ E.S. $\quad 0000-0002-8136-1240$ \\ S.K. $\quad$ 0000-0001-9417-2847 \\ B.E. $\quad$ 0000-0001-9034-6109 \\ Z.I. $\quad$ 0000-0002-3473-5051}

\section{(c) (i) (8)}

This work is licensed under a Creative Commons Attribution-NonCommercial 4.0 International License.

\section{Özet}

Renal apseler çocukluk yaş grubunda nadir görülürler. Tanıda gecikmeler böbrek kaybına neden olabilir. Tedavi yöntemi de halen tartışmalıdır. Ek hastalığı olmayan geniş spektrumlu antibiyoterapi ile regrese olmayan , organize oldugu için perkütan drenajla drene olmadığ 1 için opere ettiğimiz büyük renal apseli hasta literatür eşliğinde değerlendirildi.

Anahtar Kelimeler: Renal apse, çocukluk çağı, açık cerrahi, perkütan drenaj.
Abstract

Renal abscesses are rarely seen in the childhood period. Delays in diagnosis may cause kidney loss. The treatment method is still controversial. The patient with a large renal abscess, which we operated on because it did not regress with broad-spectrum antibiotic therapy and was not drained with percutaneous drainage because it was organized, was evaluated in the light of the literature.

Keywords: Renal abscess, childhood, open surgery, percutaneous drainage.

Cite As: Güvenç FT, Salı E, Kalın S, Elmas B, İlçe Z. Renal abscess in childhood: a case report 6 years girl. New J Urol. 2022; 17(1):58-62.

DOI: 10.33719/yud.2022;17-1-972408 


\section{INTRODUCTION}

Renal abscesses are rare in children who do not have an underlying predisposing factor, and very few cases have been reported in this regard $(1,2)$. The rare occurrence of renal abscesses causes a delay in diagnosis, which leads to kidney damage and late initiation of treatment (3). Imaging methods such as ultrasonography (USG), Computed Tomography (CT), and Magnetic Resonance (MR) are used in diagnosis $(1,4)$. The source usually spreads in an ascending manner, but there is a hematogenous spread in rare cases. While the agent in ascendant dissemination is E. Coli, the agent is Staph. aureus in a hematogenous spread. Urine analysis may give normal results in $70 \%$ of the patients, and the treatment method is still controversial. There is not enough information in the literature regarding children; thus, adult cases are often utilized. Although broad-spectrum antibiotic therapy alone may be sufficient for initial treatment, surgical intervention may also be required, especially in large-sized abscesses. Delays in diagnosis can lead to kidney damage, especially in children $(5,6)$.

In our case, an underlying predisposing factor was not found, the diagnosis was delayed, and percutaneous drainage could not be applied because the abscess was organized, and surgery had to be performed because it did not improve with long-term antibiotic therapy.

\section{CASE REPORT}

A 6-year-old female patient presented with sudden onset of fever and left flank pain, while investigating the etiology of high fever in the center where she applied, WBC: 14500 (reference range: 4000-12000/uL), CRP: 12 (reference range: $0-5 \mathrm{mg} / \mathrm{dl}$ ), there were 22 leukocytes in urine microscopy and 100,000 cfu/ml of E. Coli in urine culture. Ultrasonography (USG) revealed a $6 \mathrm{~cm}$ abscess in the left renal region. It was stated that the CT result was compatible with the abscess but could not be clearly separated from the mass due to its excessive density, and it was stated that it was not suitable for percutaneous drainage, and the material could not be drained. During the patient's follow-up, a pigtail catheter was inserted into the left thorax due to pleural effusion in the left hemithorax. Due to the absence of anything in the drainage on the day, she was referred to our clinic with pre-diagnoses of Renal Abscess and Renal Mass.

There was no specificity in her history, except for receiving outpatient medical treatment for inflammation two years ago. A pigtail catheter was present in the left thorax, and the other systemic examination gave normal results in physical examination. In laboratory tests; CRP: $12 \mathrm{mg} / \mathrm{dl}$ (reference range: $0-5 \mathrm{mg} / \mathrm{dl}$ ), sedimentation value; 69 (reference range: $1-10 \mathrm{~mm} /$ hour), and other biochemical values were within normal limits. There was no feature in the urine test, and there was no growth in the urine culture. Tuberculosis and mycobacterial examinations of the patient gave negative results, and immunological and tumor markers were normal. There was no feature in the fluid cytology sent from the thorax tube.

In the Abdomen USG, an abscess with an approximate size of $40 \times 50 \mathrm{~mm}$ extending towards the renal sinus in the upper pole cortex of the left kidney and a dense pleural effusion with a depth of $2 \mathrm{~cm}$ in the left hemithorax were observed. Abdomen MRI showed an exophytic collection at the level of the upper pole of the left kidney, $73 \times 48 \times 30 \mathrm{~mm}$ in size, at air-fluid level, compatible with an abscess that contrasted the thick wall in contrast examination (Figure-1a-1b, Figure 2). Thorax CT resulted in a septal subpulmonic pleural effusion with a depth of $14 \mathrm{~mm}$ in the left hemithorax (Figure-3). The thorax drain was removed on the 7 th day when the patient's clinical condition improved, nothing was not coming from the drain, and the PA chest radiography was normal. Antibiotic treatment was decided by the Committee of Infection, Nephrology, Radiology, and Pediatric Surgery. Since there was no growth in the urine culture and the urine culture antibiogram result with external growth was not reached, Ciprofloxacin (Ciproxin) 3x230 mg iv (10 mg/ $\mathrm{kg} /$ dose), Amikacin (Amijeksin) 3x125 mg iv (15 mg/ $\mathrm{kg} /$ day), Vancomycin (Vankopol) 4x230 mg iv (10 mg/ $\mathrm{kg} / \mathrm{dose}$ ) antibiotics were continued to be given. Percutaneous Drainage was repeated for the patient whose abscess size did not regress in the third week of treatment.

Trucut biopsy of the patient, who had no apparent improvement in drainage, showed abscess formation and pyelonephritis findings. After the USG was performed in the first month of medication treatment, 
there was no significant change in abscess size, the decision for surgery was taken in the council. Transperitoneal laparoscopy revealed that the kidney was opened to the perirenal fascia and gerota, and the upper pole was more prominent. Still, there was no extrarenal mass or abscess formation. Pus appeared in the laparoscopic puncture performed on the upper pole. The incision was enlarged up to $1 \mathrm{~cm}$. It was washed with physiological saline solution until nothing came to the cavity, and the procedure was terminated after placing two perirenal drains in the abscess cavity. There was no growth in the abscess culture taken during the procedure. The perirenal drain was removed on the 10th day, and the cavity drain on the 12th day since the patient was improving and nothing was coming to the drains. However, when the patient had fever on the postoperative 14th day, her antibiotherapy was revised as Meropenem (Merosid) $3^{\star} 800 \mathrm{mg}(120 \mathrm{mg} / \mathrm{kg} /$ day $)$, Amikacin (Amijeksin) 1X400 mg (20 mg/kg/day), Teicoplanin (Tekosit) $1^{\star} 200 \mathrm{mg}(10 \mathrm{mg} / \mathrm{kg} /$ dose) (vanco-
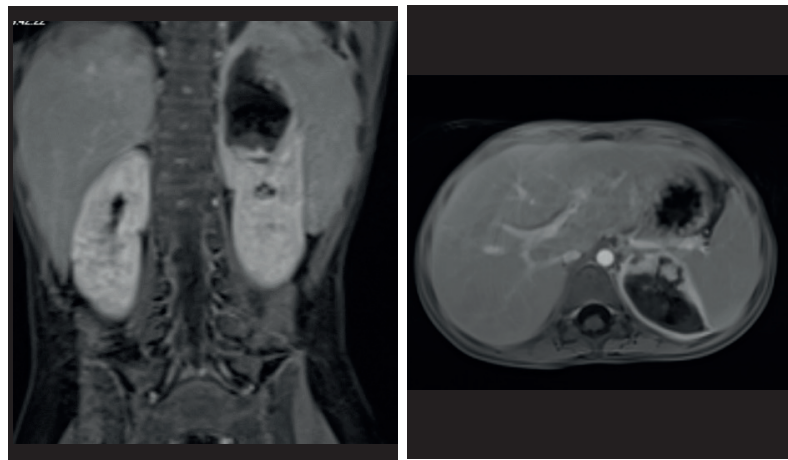

Figure 1a-1b. First Arrival Coronal and axial post-contrast T1A series

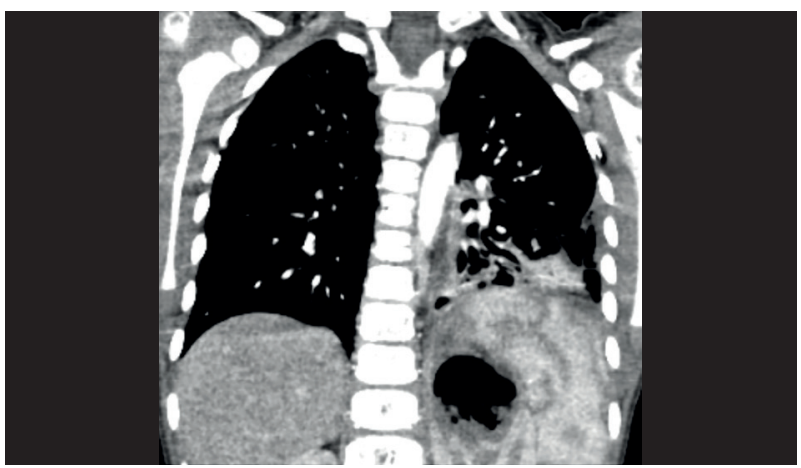

Figure 3. Thorax CT, atelectatic changes in the basal segment of the lower lobe of the left lung, and a loculated collection compatible with abscess with air densities in the upper pole of the left kidney. mycin allergy developed), and antifungal Fluconazole (Flukopol) 1x200mg (10mg/kg/day) was added. It was seen that the abscess persisted with a size of $38 \mathrm{~mm}$ in the postoperative examination and MRI results of the patient (Figure-4). As the patient's fever continued, a decision was made for another surgery on the postoperative 16th day. In the laparotomy performed on the left Lombotomy incision, the kidney was normal, but the extrarenal abscess structure in the upper pole of the kidney was approximately $1 \mathrm{~cm}$ in diameter, with an organized predominantly fibrinous character. No intrarenal or perirenal abscess was detected in the intraoperative USG. In the follow-up, the patient's general condition was good and vital signs were stable, and the control USG examination performed on the postoperative 3 rd day was evaluated as normal. The patient was discharged after completing antibiotherapy and antifungal therapy. Urination cystourethrography performed 1 month after discharge was evaluated as normal.

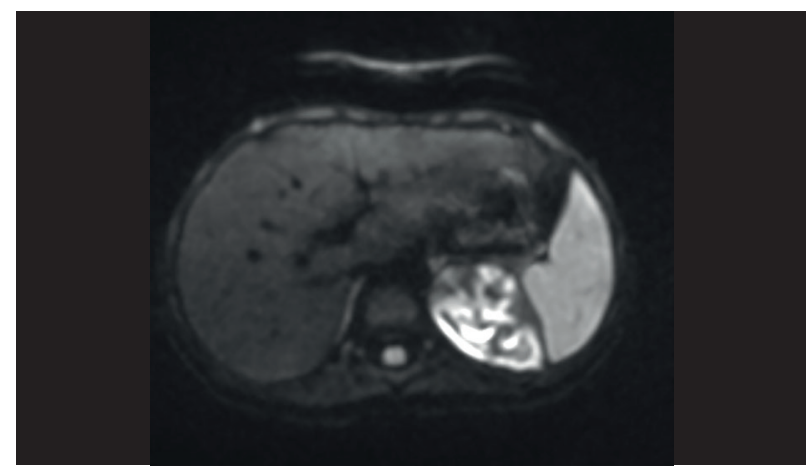

Figure 2. Significant diffusion restriction is observed in the abscess site in simultaneous diffusion-weighted examinations.

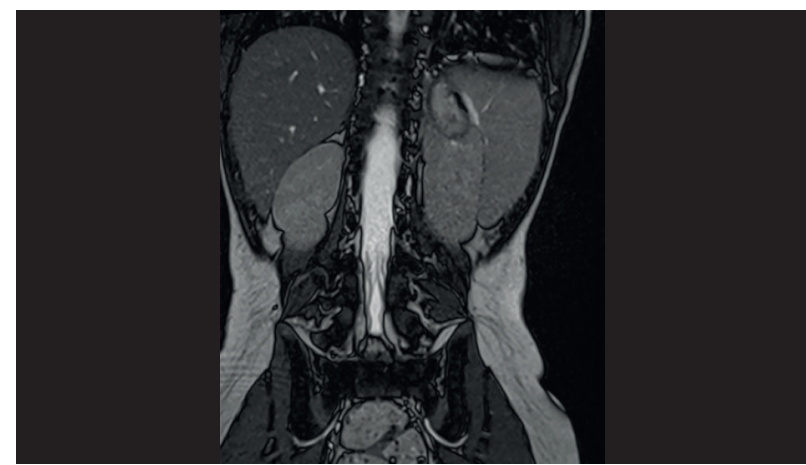

Figure 4. PO16 in coronal T2 series. Regressed abscess with a thick wall and air signals in it, according to previous reviews, under antibiotherapy on the 1st day. 


\section{DISCUSSION}

Renal abscesses are kidney infections rarely seen in pediatric patients who do not have an underlying predisposing factor (5). Suppurative material in the renal abscess is located in the cortical or corticomedullary area (4).

The frequency of renal abscesses in children is still unknown (7). It can be seen at any age, but it is more common in the young population. It is seen to three times more frequently in men compared to women. It is seen unilaterally in $77-90 \%$ and mainly in the right kidney, with 63\%. (6) In our patient, there was an abscess in the left renal region. A renal abscess is rare, and studies on children are limited.

The largest pediatric series is the series of Cheng et al., in which 45 patients were retrospectively evaluated over 10 years between 1997 and 2016. This series's most common clinical symptoms were nonspecific symptoms such as fever, nausea/vomiting, and abdominal or flank pain. It has been found that the average time taken for CT confirmation of renal abscess after the onset of symptoms is nine days. Therefore, a careful history and suspicion are essential in diagnosing renal abscesses (3).

In our case, there were nonspecific symptoms such as sudden fever and left flank pain, and tomography was performed on the 10th day of medical treatment. Laboratory tests for renal abscesses are not specific for diagnosis. Leukocytosis and elevation of inflammatory markers are common in the laboratory, and no changes may occur. There may be pyuria and leukocyturia in urinalysis, which may be complicated with pyelonephritis $(3,5)$. Conversely, urine tests may be normal if a renal or perinephric abscess develops due to hematogenous spread and does not communicate with the collecting system or if they are performed after antibiotic treatment has been initiated. It should be considered that less than half of the patients may have positive urine and blood cultures (1-2). Gram (-) bacteria are the most common cause of infections, especially E. Coli ascendancy. Staph. aureus is a common factor in the hematogenous spread and perinephric abscesses (10).

Abdominal USG, CT, and MR are cornerstones in the diagnosis of renal and perirenal abscesses. In recent years, morbidity and mortality, which was $40-50 \%$, has decreased to $1.5 \%-15 \%$ with imaging techniques (3).

Abdomen USG is the first choice because it is noninvasive and easy to apply. It has a high diagnosis rate of $70-86 \%$. On USG, the renal abscess is seen as a hypoechoic mass. The specificity and sensitivity of CT are higher (90-100\%). Better detection of abscess size is important in detecting the kidney status, additional pathologies, and treatment follow-up. On CT, the abscess wall is seen as a low-density mass in the postcentral series (4). Although the sensitivity is high, it should not be preferred except for the obligatory cases due to increased exposure to radiation.

On the other hand, MR sensitivity is higher than CT. However, general anesthesia is required for MRI in young children and babies. Since our patient was old enough, general anesthesia was not required for MRI.

Treatment of renal and perirenal abscess is medical broad spectrum antibiotherapy (including anaerobes), percutaneous drainage, open surgery, and nephrectomy.

There are publications regarding complete cure with broad-spectrum antibiotherapy and percutaneous drainage in treatment $(1,4)$. Fernandez achieved a $92 \%$ cure rate, successful treatment in 24 of 26 cases with percutaneous drainage of kidney abscesses in adults, and intravenous antibiotics (9). Siegel et al. classified abscesses in adults as small $(<3 \mathrm{~cm})$, medium $(3-5 \mathrm{~cm})$, and large $(>5 \mathrm{~cm})$. A $73 \%$ cure rate has been reported for large and medium kidney abscesses in adults when treated with parenteral antibiotics and percutaneous drainage, and it was concluded that percutaneous drainage is as adequate as open surgery. Abscesses smaller than $3 \mathrm{~cm}$ healed with 4-6 weeks of medical antibiotherapy alone (10).

Reported rates of kidney loss in children continue to be significant, $16-25 \%(1,2)$. Although a full cure is provided with broad-spectrum antibiotic therapy alone in adults, there is no information supporting this treatment modality in children. We think these patients should be treated as quickly as possible with percutaneous or open drainage to reduce the risk of kidney damage or loss (8).

Our patient was a healthy girl who had no known illness before. There were nonspecific symptoms such 
as left flank pain and fever. Her laboratory showed ESR and CRP elevation, pyuria in the first urinalysis, and E.Coli growth in the urine culture. Therefore, renal abscess due to spreading from ascending was considered. No change in blood and urine was detected in the examinations during follow-up. Although there are some protocols in treating adult renal abscesses, there is no clear information in the literature on this issue in children. Antibiotic therapy was initially applied to the patient with the council decision, but the surgery had to be performed when treatment was impossible. Percutaneous drainage failed because the abscess was organized. After surgery, the patient's clinic improved. We think that the organized fibrinous structure, which persisted with $3 \mathrm{~cm}$ after the first surgery, which did not regress despite antibiotherapy, was located in the extrarenal and was considered an abscess with the imaging methods, leaks around the drain in the renal abscess lodge. As the abscess was large, early surgery could have been performed as in adult protocols so that the hospital stay could have been shorter.

\section{CONCLUSION}

A renal abscess is an extremely rare pathology in children. Early diagnosis is very important in its treatment. Since there is no clear protocol for treatment, adult protocols can be used for effective treatment and early response to treatment. Early laparoscopic or open surgery can be performed if renal abscesses with a diameter of $>3 \mathrm{~cm}$ do not allow drainage.

\section{Conflict of Interest}

All authors declared that there is no conflict of interest.

\section{Financial Disclosure}

The authors declared that this study has received no financial support.

\section{Author Contributions}

Conception and design; FTG, Data acquisition; FTG, Data analysis and interpretation; FTG, ES, SK, Drafting the manuscript; FTG, Critical revision of the manuscript for scientific and factual content; FTG, BE, Zİ, Statistical analysis; FTG, Supervision; FTG, Zİ.

\section{REFERENCES}

1. Bellman AB. Genitourinary infections. In: Kelalis PP, King LR, BellmanAB, eds. Clinical Pediatric Urology. Philadelphia: WB SaundersCompany, 1985: 244-245.

2. Comploj E, Cassar W, Farina a, Gasparella P, Trenti E, Patermo S: Conservative management of pediatric renal abscess. Journal of PediatricUrology (2013).

3. Cheng $\mathrm{CH}$, Tsai $\mathrm{MH}, \mathrm{Su} \mathrm{LH}$, et al. Renalabscess in children: a 10-year clinical and radiological experience in a tertiary medical center. Pediatr InfectDis J. 2008;27:1025-7.

4. Emanuele Rubilotta,et al. Current clinical management of renal and perinephric abscesses. Urologia. 2014;81(3):144-147.

5. Laufer J, Grisaru-Soen G, Portnoy O, et al. Bilateral renal abscesses in a healthy child. IsrMedAssoc J. 2002;4:1150-1.

6. Evi Complojet al. Conservative management of pediatric renal abscess. Journal of pediatric urology surgery. Received 7 March 2013; accepted 15 May 2013 Available online 20 June 2013.

7. Chun-Yu Chen, Huang-Tsung Kuo, Yu-Jun Chang et al. Clinical assessment of children with renal abscesses presenting to the pediatric emergency department BMC. Pediatrics. 2016;16:189.

8. Angel C, Shu T, Green J et al. Renal and peri-renal abscesses in children: proposed physiopathological mechanisms and treatment algorithm. Pediatr Surg Int. 2003;19(1-2):35-39.

9. Fernandez JA, Miles BJ, Buck AS, Gibbons RP (1985) Renal carbuncle: comparison between surgical open drainage and closed percutaneous drainage. Urology. 25:142-144.

10. Siegel JF, Smith A, Moldwin R (1996) Minimally invasive treatment of renal abscess. J Urol. 1996;155(1);52-55. 